\title{
Analyzing the potential for using active filters to reduce voltage nonsinusoidality in the electric power supply system of a coal open-cut in Vietnam
}

\author{
Bui Ngoc Hung ${ }^{2}$, Lidiia I. Kovernikova ${ }^{1,2^{*}}$ \\ ${ }^{1}$ Melentiev Energy Systems Institute SB RAS, Irkutsk, Russia \\ ${ }^{2}$ Irkutsk National Research Technical University, Irkutsk, Vietnam
}

\begin{abstract}
Coal mining is one of the important economic sectors in Vietnam. Power supply systems of coal mines and open-cuts are complex. They have multiple levels of voltages and different types of loads. New electrical equipment usually works alongside with the equipment that is obsolete and worn-out. Power supply systems of industrial areas of Vietnam where coal is mined are characterized by the low power quality. In Vietnam the indices which characterize the distortion of both voltage and current waveforms have standard values. The article presents the findings upon the analysis of a power supply system of a coal open-cut in Vietnam and the electrical equipment of the coal sorting plant along with the results of the experimental studies of power quality indices and the non-sinusoidal mode parameters. The measurement analysis has shown that the indices of the 5-th and 7-th harmonics of voltage were over the limits. There are interharmonics in voltages and currents. The article analyzes the characteristics of active filters. It is possible to improve the power quality by using an active filter which generates both reactive power to increase the load power factor and harmonic and interharmonic currents to reduce the degree of voltage and current waveform distortion.
\end{abstract}

\section{Introduction}

Coal mining is one of the important economic sectors in Vietnam. Power supply systems of coal mines and open-cuts are complex. They have multiple levels of voltages and different types of loads. New electrical equipment usually works alongside with the equipment that is obsolete and worn-out. There are high-power loads including non-linear ones which distort the parameters of the electric network modes and, thus deteriorate the power quality. Power supply systems of industrial areas of Vietnam where coal is mined are characterized by the low power quality.

In Russia the degree of voltage waveform distortion is limited to the standard values specified for the $K_{U}$ and $K_{U(n)}$ indices in [1]. In Vietnam the indices which characterize the distortion of both voltage and current waveforms have standard values specified in $[2,3]$.

This article analyzes a power supply system scheme of one of the coal open-cuts in Vietnam, its loads, the power quality based on the measurements of power quality indices and harmonics mode parameters. It also analyzes the characteristics of active filters that could be used to improve the power quality in the coal opencut.

\section{Power supply system of a coal open- cut}

The power supply system of a coal open-cut is given on Fig. 1. The diagram makes it clear that the power is supplied to the coal open-cut from a $110 \mathrm{kV}$ twotransformer substation, which is powered from two independent sources via $110 \mathrm{kV}$ transmission lines. One of the transformers is in working condition and the other is in reserve. There are two $22 \mathrm{kV}$ busbar sections (6604 and 6643 nodes) on the low-voltage side of the transformers. The electric power is supplied to the coal open-cut from the $22 \mathrm{kV}$ busbar section (node 6643) through a $22 / 0.4 \mathrm{kV}$ step-down transformer.

Coal is mined using an excavator and then transported by conveyors to a sorting plant for processing. The sorting plant has two coal-sorting shops and an electric power and water supply shop. The total length of power lines of all voltages $(110,22$ and $0.4 \mathrm{kV}$ ) is about $60 \mathrm{~km}$. Reactive power sources $450 \mathrm{kVAr}$ capacitors - are connected to the $0.4 \mathrm{kV}$ buses.

The sorting plant has various processing equipment: vibration generators, breaker machinery, conveyors, winches, pumps, etc. Most of this equipment is powered by asynchronous motors with power ranging from 4 to $185 \mathrm{~kW}$.

kovernikova@isem.irk.ru 


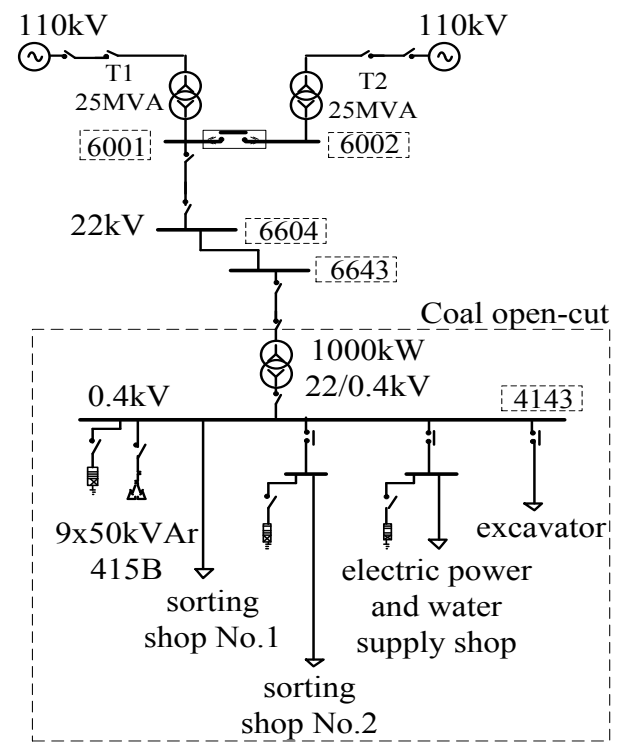

Fig. 1. Power supply system of a coal open-cut.

Coal processing consists in sorting the coal pieces by size using vibrating screen. The operational procedure of coal processing in the sorting shop No.1 is shown in Fig. 2, where d is a diameter of coal pieces.

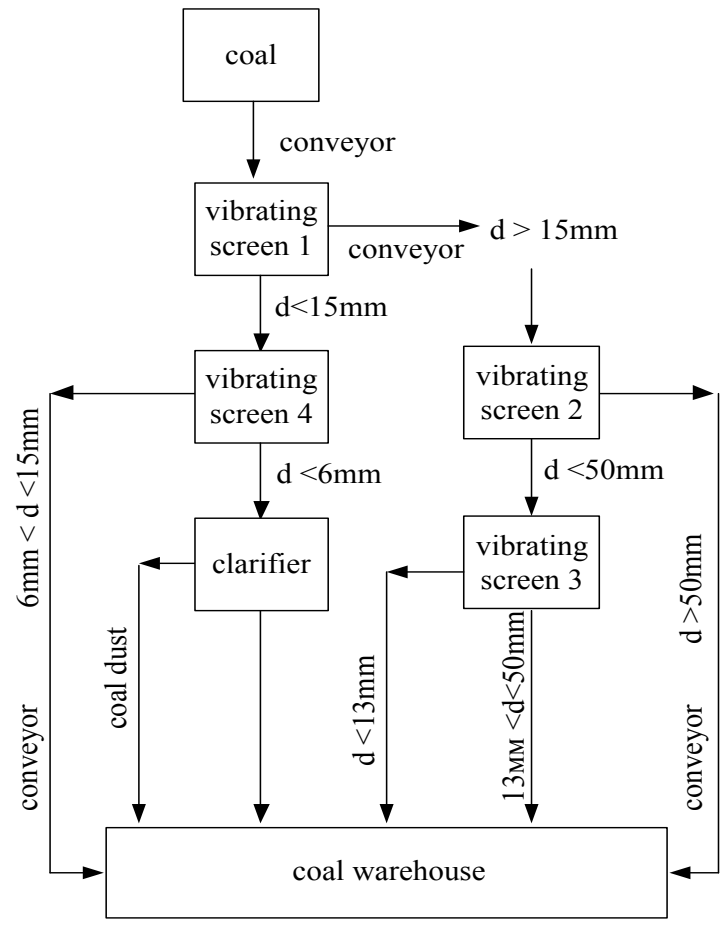

Fig. 2. Operational procedure of sorting shop No.1.

There are 17 units of electrical equipment in the sorting shop No.1. The power range of electric motors is $4-50 \mathrm{~kW}$. The sorting shop hours are from 7 a.m. to 5 p.m. From 5 p.m. to 7 a.m. of the next day there is a break and the main processing equipment does not work. At this time only the electrical equipment of the electric power and water supply shop is functional.

Coal processing continues in the sorting shop No.2. 18 units of electrical equipment with asynchronous motors with power ranging from 4 to $185 \mathrm{~kW}$ are involved in the operational procedure. The sorting shop No. 2 continuously operates from 7 a.m. to 5 p.m. After 5 p.m. water pumps and mixers remain in operation continuing the special technological process.

The electric power and water supply shop which provides lighting to the sorting shops, supplies water to the sorting plant and ensures coal transportation to a warehouse has 23 units of electrical equipment. The power range of electric motors is from 4 to $160 \mathrm{~kW}$.

In general frequency regulated asynchronous motors are used at the sorting plant. Fig. 3 shows the asynchronous motor diagram.

Frequency regulated asynchronous motor consumes non-sinusoidal current. It is a non-linear load, i.e. a source of harmonic and interharmonic currents causing the power quality degradation. To assess the power quality the power quality indices and the nonsinusoidal mode parameters were measured. The measurement results are provided below.

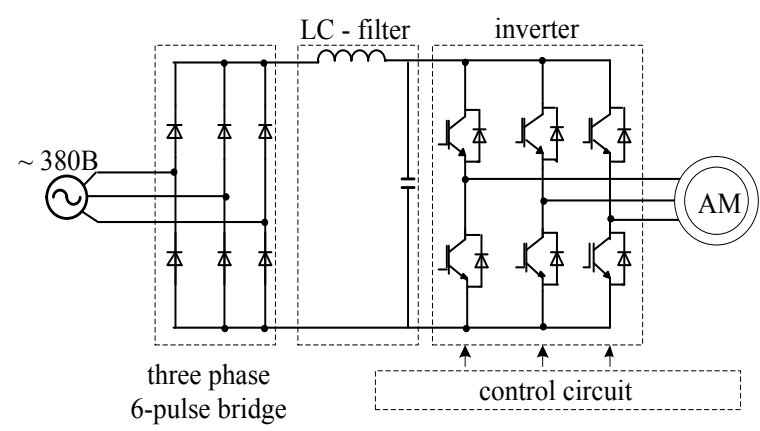

Fig. 3. Frequency regulated asynchronous motor diagram.

\section{Results of the power quality and mode parameters measurement}

The measurements were carried out using a PQ-Box 150 tool made in Germany. The measurements of the power quality indices and mode parameters were being taken from the low-voltage side of a $22 / 0.4 \mathrm{kV}$ stepdown transformer at node 4143 in the course of 24 hours with a one second interval.

\subsection{Results of the active and reactive power measurement}

Fig. 4 shows the curves of changes in the active and reactive power values in three phases consumed by the load of the coal open-cut during 24 hours of measurement. The maximum active power consumption was $1035 \mathrm{~kW}$, maximum reactive power consumption was $419 \mathrm{kVAr}$. At night time electrical equipment which consumes $203 \mathrm{~kW}$ of active power and $94 \mathrm{kVAr}$ of reactive power is in operation.

Table 1 provides statistical estimates of reactive power and $\cos \varphi$ values during working hours and breaks. In the Table: Max and Min - the maximum and minimum values, $\mathrm{EV}$ - the average value, $\mathrm{SV}$ - the 
standard value. The Table shows that although the $450 \mathrm{kVAr}$ capacitors are installed for reactive power compensation, the average value of the power factor in phase B is 0.83 which is less than 0.85 (the standard value) specified in [2]. This is a reason why the company that owns the coal open-cut has to pay a fine every month.

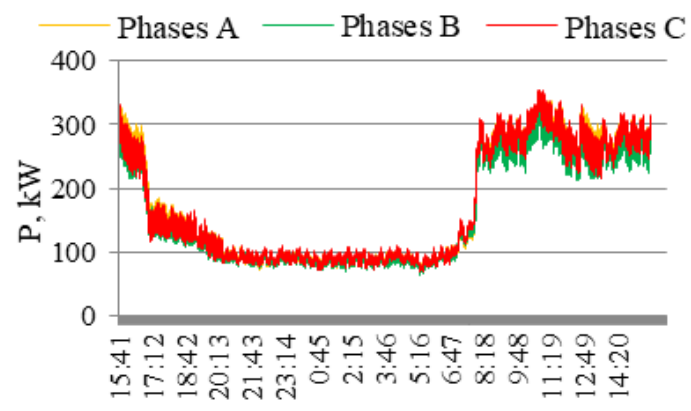

Time, hour: $\min$

a)

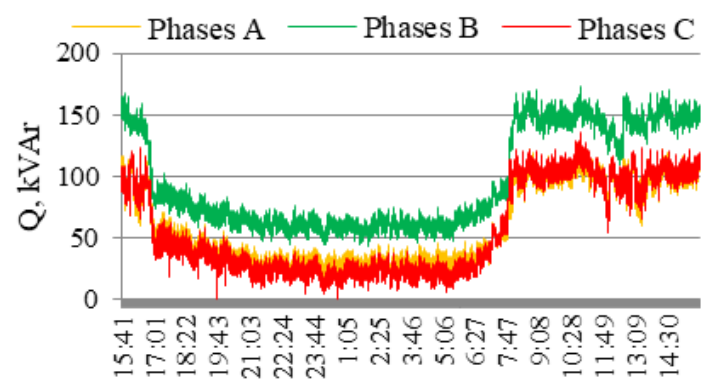

Time, hour: $\min$

b)

Fig. 4. Daily a) active and b) reactive power consumption chart.

Table 1. Statistical estimates of reactive power and $\cos \varphi$.

\begin{tabular}{|c|c|c|c|c|c|c|}
\hline \multirow{3}{*}{ Value } & \multicolumn{6}{|c|}{ Working time } \\
\hline & \multicolumn{2}{|c|}{ Phases A } & \multicolumn{2}{|c|}{ Phases B } & \multicolumn{2}{|c|}{ Phases C } \\
\hline & $\begin{array}{c}\mathrm{Q}, \\
\mathrm{kVAr}\end{array}$ & $\cos \varphi_{A}$ & $\begin{array}{c}\mathrm{Q}, \\
\mathrm{kVAr}\end{array}$ & $\cos \varphi_{B}$ & $\begin{array}{c}\mathrm{Q}, \\
\mathrm{kVAr}\end{array}$ & $\cos \varphi_{C}$ \\
\hline Max & 127.1 & 0.97 & 173 & 0.91 & 136 & 0.97 \\
\hline Min & 28.6 & 0.89 & 67 & 0.77 & 29 & 0.89 \\
\hline EV & 94.5 & 0.94 & 140 & 0.83 & 96.8 & 0.93 \\
\hline SV & & $\geq 0.85$ & & $\geq 0.85$ & & $\geq 0.85$ \\
\hline \multirow{3}{*}{ Value } & \multicolumn{6}{|c|}{ Break time } \\
\hline & \multicolumn{2}{|c|}{ Phases A } & \multicolumn{2}{|c|}{ Phases B } & \multicolumn{2}{|c|}{ Phases C } \\
\hline & $\begin{array}{c}\mathrm{Q}, \\
\mathrm{kVAr}\end{array}$ & $\cos \varphi_{A}$ & $\begin{array}{c}Q, \\
\mathrm{kVAr}\end{array}$ & $\cos \varphi_{B}$ & $\begin{array}{c}\mathrm{Q}, \\
\text { kVAr }\end{array}$ & $\cos \varphi_{C}$ \\
\hline Max & 71.5 & 0.98 & 102.7 & 0.92 & 64.9 & 0.99 \\
\hline Min & 14.9 & 0.89 & 43.7 & 0.72 & 0.00 & 0.91 \\
\hline EV & 34.9 & 0.94 & 65.9 & 0.81 & 28.2 & 0.96 \\
\hline SV & & $\geq 0.85$ & & $\geq 0.85$ & & $\geq 0.85$ \\
\hline
\end{tabular}

\subsection{Results of voltage harmonics measurement}

Fig. 5 shows a diagram of the $n$-th voltage harmonic indices for the minimum $\left(K_{U(n) \min }\right)$ and maximum $\left(K_{U(n) \max }\right)$ load modes. For most harmonics $K_{U(n)}$ in the maximum load mode exceed the values in the minimum load mode.

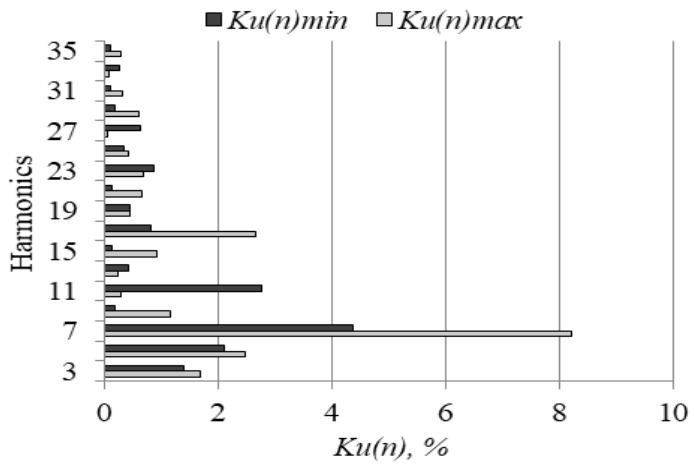

Fig. 5. Phase A voltage harmonics diagram.

Fig. 6 shows a graph of the change in the power quality index - the total harmonic distortion of voltage $K_{U}$ in phase $\mathrm{A}$ and the standard value $K_{U S}$. The figure shows that most of the measured $K_{U}$ values exceed the standard value of $6.5 \%$ specified in [2]. The largest $K_{U}$ value is $16.7 \%$, the smallest value $-3.8 \%$, the average $-9.2 \%$.

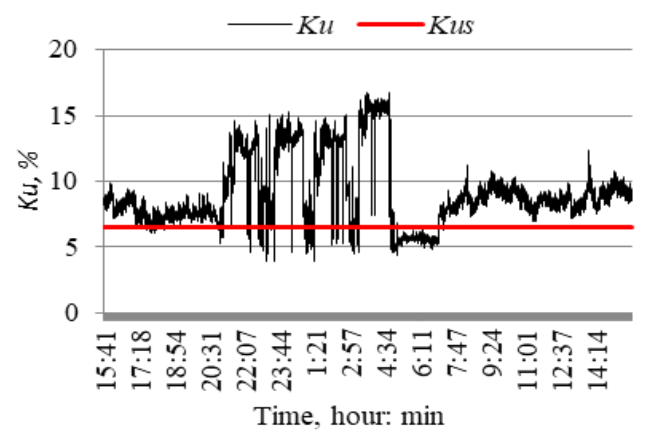

Fig. 6. Changes of the total harmonic distortion of voltage in phase A.

Tables 2 and 3 show the statistical estimates of $K_{U(n)}$ in phase A for the operation time and break time.

Table 2. Statistical estimates of $K_{U(n)}$ for working time, \%.

\begin{tabular}{|l|c|c|c|c|c|c|c|c|}
\hline \multirow{2}{*}{ Value } & \multicolumn{10}{|c|}{ Harmonics } \\
\cline { 2 - 10 } & 3 & 5 & 7 & 9 & 11 & 13 & 15 & 17 \\
\hline Max & 2.5 & 6.2 & 11 & 1.9 & 3.0 & 2.1 & 1.8 & 3.3 \\
\hline Min & 0.6 & 1.1 & 3.4 & 0.3 & 0.1 & 0.1 & 0.1 & 0.1 \\
\hline EV & 1.5 & 3.4 & 7.1 & 1.0 & 0.6 & 0.7 & 0.8 & 1.4 \\
\hline SV & \multicolumn{10}{|c|}{$\leq 3.0$} \\
\hline \multirow{2}{*}{ Value } & \multicolumn{10}{|c|}{ Harmonics } \\
\cline { 2 - 10 } & 19 & 21 & 23 & 25 & 27 & 29 & 31 & 33 \\
\hline Max & 1.6 & 1.5 & 2.9 & 1.9 & 1.1 & 1.9 & 1.0 & 0.6 \\
\hline Min & 0.1 & 0.1 & 0.1 & 0.1 & 0.1 & 0.1 & 0.1 & 0.1 \\
\hline EV & 0.5 & 0.6 & 0.9 & 0.6 & 0.3 & 0.6 & 0.3 & 0.2 \\
\hline SV & \multicolumn{10}{|c|}{$\leq 3.0$} \\
\hline
\end{tabular}

The standard value for $K_{U(n)}$ equal to $3 \%$ is exceeded on the 5-th and 7-th harmonics, the sources of which are three-phase 6-pulse rectification circuits that feed the frequency regulated asynchronous motors. 
Table 3. Statistical estimates of $K_{U(n)}$ for break time, $\%$.

\begin{tabular}{|c|c|c|c|c|c|c|c|c|}
\hline \multirow{2}{*}{ Value } & \multicolumn{8}{|c|}{ Harmonics } \\
\hline & 3 & 5 & 7 & 9 & 11 & 13 & 15 & 17 \\
\hline Max & 2.1 & 12.7 & 12.8 & 1.6 & 4.6 & 1.9 & 0.8 & 1.5 \\
\hline Min & 0.5 & 0.1 & 1.4 & 0.1 & 0.1 & 0.1 & 0.1 & 0.1 \\
\hline EV & 1.2 & 5.4 & 6.9 & 0.8 & 1.8 & 0.5 & 0.3 & 0.7 \\
\hline SV & \multicolumn{8}{|c|}{$\leq 3.0$} \\
\hline \multirow{2}{*}{ Value } & \multicolumn{8}{|c|}{ Harmonics } \\
\hline & 19 & 21 & 23 & 25 & 27 & 29 & 31 & 33 \\
\hline Max & 1.5 & 2.1 & 3.1 & 1.8 & 1.1 & 1.4 & 0.9 & 0.8 \\
\hline Min & 0.1 & 0.1 & 0.1 & 0.1 & 0.1 & 0.1 & 0.1 & 0.1 \\
\hline EV & 0.4 & 0.3 & 0.8 & 0.4 & 0.3 & 0.3 & 0.1 & 0.2 \\
\hline SV & & & & & & & & \\
\hline
\end{tabular}

Fig. 7 shows the graphs of changes in the measured $K_{U(5)}$ and $K_{U(7)}$ indices in phase A. It is clear that $K_{U(5)}$ and $K_{U(7)}$ values exceed the standard value of $3 \%$, established in [2] during a significant part of the measurement. They have the largest values during a break in work.

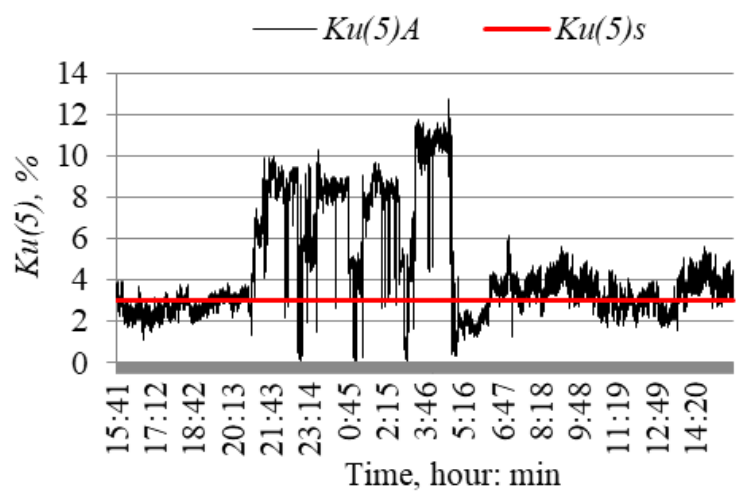

a)

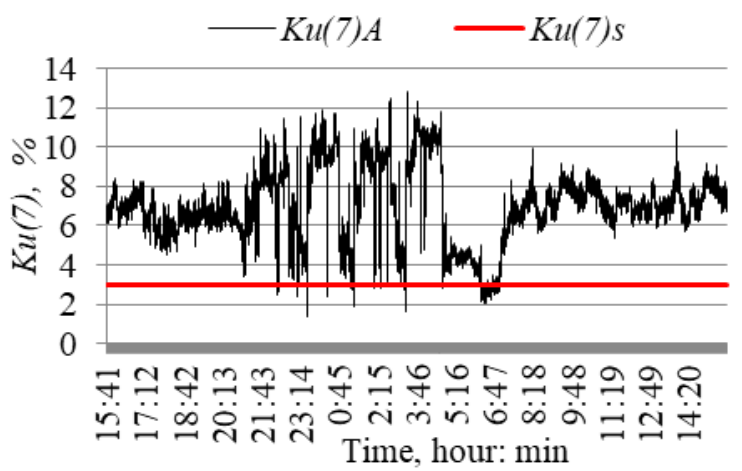

b)

Fig. 7. Changes in measured indices a) $K_{U(5)}$ and b) $K_{U(7)}$ in phase A.

\subsection{Results of current harmonics measurement}

Tables 4 and 5 provide statistical estimates of coefficients of the $n$-th current harmonics $K_{I(n)}$ for some harmonics in phase A. The tables show that $K_{I(n)}$ values do not exceed the standard value of $12 \%$ specified in [3]. The largest coefficients values are on the 3-rd, 5-th and 7-th harmonics, notably, during the break in work.
Table 4. Statistical estimates of $K_{I(n)}$ for working time, $\%$.

\begin{tabular}{|l|c|c|c|c|c|c|c|c|}
\hline \multirow{2}{*}{ Value } & \multicolumn{10}{|c|}{ Harmonics } \\
\cline { 2 - 10 } & 3 & 5 & 7 & 9 & 11 & 13 & 15 & 17 \\
\hline Max & 5.6 & 6.0 & 3.4 & 2.2 & 1.2 & 1.5 & 1.0 & 1.9 \\
\hline Min & 1.6 & 0.4 & 0.4 & 0.4 & 0.0 & 0.0 & 0.0 & 0.1 \\
\hline EV & 3.3 & 3.6 & 1.4 & 1.0 & 0.3 & 0.6 & 0.4 & 0.7 \\
\hline SV & \multicolumn{10}{|c|}{$\leq 12.0$} \\
\hline \multirow{2}{*}{ Value } & \multicolumn{10}{|c|}{} \\
\cline { 2 - 9 } & 19 & 21 & 23 & 25 & 27 & 29 & 31 & 33 \\
\hline Max & 1.3 & 0.8 & 2.7 & 1.1 & 0.6 & 1.1 & 0.6 & 0.3 \\
\hline Min & 0.0 & 0.0 & 0.0 & 0.0 & 0.0 & 0.1 & 0.0 & 0.0 \\
\hline EV & 0.3 & 0.2 & 0.5 & 0.3 & 0.1 & 0.2 & 0.1 & 0.0 \\
\hline SV & \multicolumn{10}{|c|}{$\leq 12.0$} \\
\hline
\end{tabular}

Table 5. Statistical estimates of $K_{I(n)}$ for break time, $\%$.

\begin{tabular}{|l|c|c|c|c|c|c|c|c|}
\hline \multirow{2}{*}{ Value } & \multicolumn{10}{|c|}{ Harmonics } \\
\cline { 2 - 10 } & 3 & 5 & 7 & 9 & 11 & 13 & 15 & 17 \\
\hline Max & 7.1 & 6.8 & 6.7 & 2.9 & 3.9 & 1.9 & 1.2 & 2.3 \\
\hline Min & 1.7 & 0.0 & 0.3 & 0.7 & 0.0 & 0.0 & 0.0 & 0.2 \\
\hline EV & 4.0 & 2.0 & 2.8 & 1.6 & 1.3 & 0.7 & 0.5 & 1.0 \\
\hline SV & \multicolumn{10}{|c|}{$\leq 12.0$} \\
\hline \multirow{2}{*}{ Value } & \multicolumn{10}{|c|}{} \\
\cline { 2 - 9 } & 19 & 21 & 23 & 25 & 27 & 29 & 31 & 33 \\
\hline Max & 1.9 & 2.3 & 2.5 & 2.4 & 1.3 & 1.2 & 0.6 & 0.8 \\
\hline Min & 0.0 & 0.0 & 0.1 & 0.0 & 0.0 & 0.0 & 0.0 & 0.0 \\
\hline EV & 0.5 & 0.4 & 1.0 & 0.5 & 0.3 & 0.3 & 0.2 & 0.1 \\
\hline SV & \multicolumn{10}{|c|}{$\leq 12.0$} \\
\hline
\end{tabular}

\subsection{Results of voltage and current interharmo- nics measurement}

Unlike harmonics, interharmonics have fractional numbers. Their frequency is not multiple to the fundamental frequency of $50 \mathrm{~Hz}$. Interharmonics appear when working with loads such as static frequency converters. They have a major influence on the electrical network mode since they cause additional electric power losses [4]. The Russian [1] and Vietnamese [2, 3] regulatory documents on the power quality do not provide any indices characterizing interharmonics nor any limits for their values.

When measuring the power quality indices and the non-sinusoidal mode parameters, the voltage and current values of interharmonic centered subgroups were determined [12]. The frequency of the interharmonic centered subgroup is defined as the average of two multiple frequencies, i.e.

$$
f_{\text {isg }, n}=\left(f_{n}+f_{n+1}\right) / 2 \text {, }
$$

where $n$ - a harmonic number, isg - is interharmonic centered subgroup.

Tables 6-9 provide the statistical estimates of voltage and current values for interharmonic centered subgroups in phase A for both the operation time and break time. The interharmonic number, represented, for example, as 1-2, means that the interharmonic number of the centered subgroup is $n=(1+2) / 2=1.5$.

From the data provided in tables 6-9, it follows that during working hours the interharmonic voltage and current values exceed the values of the interharmonics during a break in work. The measurement results demonstrate that the coal open-cut loads are sources of 
the current harmonics and interharmonics, which cause the voltage harmonics and interharmonics.

Table 6. Statistical estimates of the voltage values of interharmonic centered subgroups for working time, $\%$.

\begin{tabular}{|l|c|c|c|c|c|c|c|c|}
\hline \multirow{3}{*}{ Value } & \multicolumn{7}{|c|}{ Interharmonics } \\
\cline { 2 - 10 } & $\begin{array}{c}1- \\
2\end{array}$ & $3-4$ & $5-6$ & $\begin{array}{c}7- \\
8\end{array}$ & $\begin{array}{c}9- \\
10\end{array}$ & $\begin{array}{c}11- \\
12\end{array}$ & $\begin{array}{c}13- \\
14\end{array}$ & $\begin{array}{c}15- \\
16\end{array}$ \\
\hline Max & 3.9 & 1.1 & 1.7 & 1.8 & 1.0 & 1.3 & 1.3 & 0.9 \\
\hline Min & 0.1 & 0.1 & 0.1 & 0.1 & 0.0 & 0.0 & 0.1 & 0.1 \\
\hline EV & 0.2 & 0.1 & 0.1 & 0.1 & 0.0 & 0.1 & 0.1 & 0.1 \\
\hline \multirow{8}{*}{ Value } & \multicolumn{7}{|c|}{ Interharmonics } \\
\cline { 2 - 10 } & $17-$ & $19-$ & $21-$ & $23-$ & $25-$ & $27-$ & $29-$ & $31-$ \\
& 18 & 20 & 22 & 24 & 26 & 28 & 30 & 32 \\
\hline Max & 1.2 & 1.5 & 2.3 & 2.9 & 2.3 & 1.4 & 1.3 & 0.8 \\
\hline Min & 0.1 & 0.1 & 0.1 & 0.1 & 0.1 & 0.1 & 0.0 & 0.0 \\
\hline EV & 0.1 & 0.1 & 0.1 & 0.1 & 0.1 & 0.1 & 0.0 & 0.03 \\
\hline
\end{tabular}

Table 7. Statistical assessment of the values of voltage interharmonic centered subgroups for break time, \%.

\begin{tabular}{|l|c|c|c|c|c|c|c|c|}
\hline \multirow{3}{*}{ Value } & \multicolumn{7}{|c|}{ Interharmonics } \\
\cline { 2 - 10 } & $1-$ & $3-4$ & $5-6$ & $\begin{array}{c}7- \\
8\end{array}$ & $9-$ & $11-$ & $13-$ & $15-$ \\
12 & 14 & 16 \\
\hline Max & 1.6 & 1.0 & 1.6 & 1.8 & 1.0 & 1.3 & 0.9 & 0.8 \\
\hline Min & 0.1 & 0.0 & 0.0 & 0.0 & 0.0 & 0.0 & 0.0 & 0.0 \\
\hline EV & 0.2 & 0.1 & 0.1 & 0.1 & 0.1 & 0.1 & 0.0 & 0.0 \\
\hline \multirow{3}{*}{ Value } & \multicolumn{7}{|c|}{ Interharmonics } \\
\cline { 2 - 10 } & $17-$ & $19-$ & $21-$ & $23-$ & $25-$ & $27-$ & $29-$ & $31-$ \\
& 18 & 20 & 22 & 24 & 26 & 28 & 30 & 32 \\
\hline Max & 1.1 & 0.9 & 2.2 & 2.8 & 2.2 & 1.3 & 1.3 & 0.8 \\
\hline Min & 0.0 & 0.0 & 0.0 & 0.0 & 0.0 & 0.0 & 0.0 & 0.0 \\
\hline EV & 0.0 & 0.1 & 0.1 & 0.1 & 0.1 & 0.1 & 0.0 & 0.0 \\
\hline
\end{tabular}

Table 8. Statistical estimates of the values of the current of the interharmonic centered subgroup for working time, A.

\begin{tabular}{|l|c|c|c|c|c|c|c|c|}
\hline \multirow{3}{*}{ Value } & \multicolumn{7}{|c|}{ Interharmonics } \\
\cline { 2 - 9 } & $1-$ & $3-$ & $5-6$ & $7-$ & $9-$ & $11-$ & $13-$ & $15-$ \\
10 & 12 & 14 & 16 \\
\hline Max & 16.6 & 6.0 & 4.6 & 4.0 & 3.9 & 5.1 & 5.1 & 4.5 \\
\hline Min & 0.7 & 0.1 & 0.1 & 0.1 & 0.1 & 0.1 & 0.1 & 0.1 \\
\hline EV & 3.7 & 0.8 & 0.6 & 0.4 & 0.3 & 0.3 & 0.3 & 0.3 \\
\hline \multirow{8}{*}{ Value } & \multicolumn{7}{|c|}{ Interharmonics } \\
\cline { 2 - 10 } & $17-$ & $19-$ & $21-$ & $23-$ & $25-$ & $27-$ & $29-$ & $31-$ \\
& 18 & 20 & 22 & 24 & 26 & 28 & 30 & 32 \\
\hline Max & 7.5 & 8.5 & 6.6 & 4.2 & 3.4 & 2.9 & 2.4 & 2.1 \\
\hline Min & 0.1 & 0.1 & 0.1 & 0.1 & 0.1 & 0.1 & 0.1 & 0.0 \\
\hline EV & 0.4 & 0.3 & 0.3 & 0.3 & 0.2 & 0.1 & 0.1 & 0.1 \\
\hline
\end{tabular}

Table 9. Statistical estimates of the values of the current of the interharmonic centered subgroup for the break time, A.

\begin{tabular}{|l|c|c|c|c|c|c|c|c|}
\hline \multirow{3}{*}{ Value } & \multicolumn{8}{|c|}{ Interharmonics } \\
\cline { 2 - 10 } & $1-2$ & $3-$ & $5-$ & $7-$ & $9-$ & $11-$ & $13-$ & $15-$ \\
& & 4 & 6 & 8 & 10 & 12 & 14 & 16 \\
\hline Max & 12.9 & 5.3 & 5.1 & 4.3 & 3.7 & 4.0 & 3.6 & 3.6 \\
\hline Min & 0.6 & 0.1 & 0.1 & 0.1 & 0.1 & 0.1 & 0.1 & 0.1 \\
\hline EV & 1.8 & 0.3 & 0.3 & 0.2 & 0.2 & 0.3 & 0.2 & 0.2 \\
\hline \multirow{8}{*}{ Value } & $17-$ & $19-$ & $21-$ & $23-$ & $25-$ & $27-$ & $29-$ & $31-$ \\
\cline { 2 - 10 } & 18 & 20 & 22 & 24 & 26 & 28 & 30 & 32 \\
\hline Max & 4.6 & 4.8 & 9.6 & 13.1 & 12.5 & 7.0 & 7.5 & 5.4 \\
\hline Min & 0.1 & 0.1 & 0.1 & 0.1 & 0.0 & 0.0 & 0.0 & 0.0 \\
\hline EV & 0.3 & 0.3 & 0.6 & 0.7 & 0.5 & 0.2 & 0.1 & 0.1 \\
\hline
\end{tabular}

$K_{U(5)}$ and $K_{U(7)}$ indices exceed the standard value of $3 \%$, established in [2] both during the operation time and break time. To reduce the $K_{U(5)}$ and $K_{U(7)}$ values to the standard value, it is necessary to apply special measures for example to install an active filter.

\section{Characteristics of active filters}

The operating principles of active filters were developed in the 1970s. Recently, a closer attention has been paid to these filters due to the introduction of bipolar transistors with insulated gate and digital signal processors $[5,6]$.

The operating principle of the active filter is as follows: the power electronics of a filter generates current harmonics into the electrical network, which are equal in magnitude to the harmonics of the currents consumed by the non-linear load but with the opposite phase. The load current is measured by a current transformer and then analyzed by a digital signal processor to determine the spectrum of current harmonics, their magnitude and phase. The obtained information is used by a generator of current harmonics to produce current harmonics into the network in the next period. These harmonics will have the values and phases required to compensate for the current harmonics and the reactive power consumed by a nonlinear load. Considering that the active filter is controlled using the data received from the current transformer, it dynamically adapts to the changes in load current harmonics. The software controls the processes of analysis and current harmonics generation, so the active filter is easily programmed to compensate for any harmonics.

The active filters are classified according to the output power value [7]. The filter selected for harmonic currents compensation should match the non-linear load power and the reactive power it consumes.

The rated power of low power active filters is under $100 \mathrm{kVA}$. These filters are intended for three-phase networks of residential areas, business buildings, hospitals, for small and medium factory loads and enterprises using electric drives. The response rate of the low power active filter to the change in the load current harmonics is within tens of microseconds and milliseconds. During this time active filters produce current harmonics and reactive power into the network in compliance with the needs of the electrical network at the filter installation site $[5,8]$.

The rated power of average power active filters ranges from $100 \mathrm{kVA}$ to $10 \mathrm{MVA}$. They are intended for use in three-phase distribution networks of medium and high voltage, including under a minor voltage unbalance. For economic reasons, high-voltage distribution networks do not use active filters for reactive power compensation, since insulation problems arise. The response rate of the average power active filter to the change in the load current harmonics is tens of milliseconds.

The rated power of high power active filters is over 10 MVA. They are very expensive since currently there 
is no electronic equipment, which operates at high voltage and at high frequencies. To ensure the operation of these filters, they should be provided with special current sensors and instrument transformers, which should operate at high voltages and high currents. The response rate of the high power active filter is tens of seconds. This is necessary for the operation of electric contactors and circuit breakers once the optimal decision about switching the transistors is made.

Based on the grid connection method with regard to a non-linear load, series and parallel active filters are distinguished. A parallel active filter is used both to compensate for current harmonics and for reactive power of a non-linear load [9]. Fig. 8a shows a configuration of a parallel filter connection to the network. Fig. 8b demonstrates a connection configuration of a series active filter. A voltage source is the electrical network and a current source is a nonlinear load.

In the figures: $\dot{U}_{C}-$ a network voltage vector, $\dot{I}_{C}-$ a network current vector, $Z_{C}-$ network impedance, $\dot{I}_{f}-$ a filter current vector, $Y_{H}$ - non-linear load admittance, $\dot{I}_{H}$ - a current source vector of the nonlinear load, $U_{D C}-\mathrm{DC}$ voltage of a filter capacitor, $L_{f}-$ filter inductance, $C_{f}-\mathrm{a}$ filter capacitor.

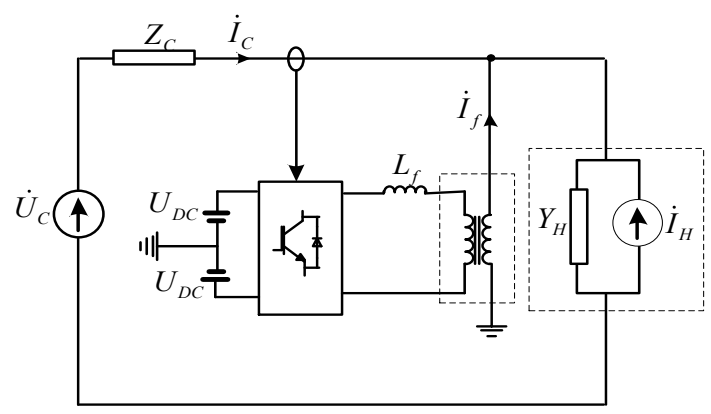

a)

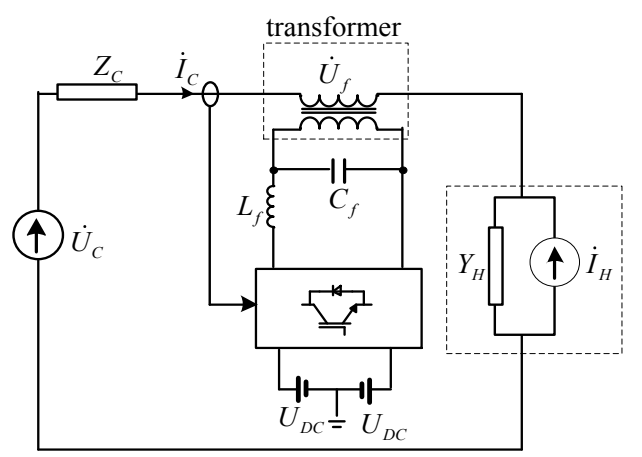

b)

Fig. 8. Diagrams of connection to the network of a) parallel active filter and $b$ ) series active filter.

Series active filters [10] are used when only current harmonics compensation is required. They are connected between the mains voltage source and the non-linear load through three-phase transformers or three single-phase transformers as shown in Fig. 8b.
The main disadvantage of the series active filter is the need to withstand large currents of load in the secondary winding of the connecting transformer, which increases the series filter rated current compared to a parallel filter. The main advantage of the series filters over parallel filters consists in the fact that they could be used for voltage harmonics cancellation and three-phase voltage balancing [11].

\section{Conclusion}

The analysis of the coal open-cut power supply scheme, the electrical equipment composition at the sorting plant, the measurement results for power quality indices and the non-sinusoidal mode parameters along with the characteristics of active filters suggest that an active filter can be used to reduce voltage and current nonsinusoidality so that it meets the requirements specified in the power quality regulations accepted in Vietnam. When choosing the type, power and parameters of the active filter, it is necessary to carefully analyze the measurement results, mode parameters of the network, where it is going to be installed, both at the harmonic and interharmonic frequencies and at fundamental frequency.

This work is conducted in the framework of the research projects № AAAA-A17-117030310438-1 of the program of fundamental research of SB RAS III.17.4.

\section{References}

1. GOST 32144-2013, Electric energy. Electromagnetic compatibility of technical equipment. Power quality limits in public power supply systems (2014)

2. Circular No. 39/2015/TT-BCT for the distribution of electric energy of the Ministry of Industry and Trade of Vietnam dat.11/18/2015 (2016)

3. Circular No. 25/2016/TT-BCT on the transmission of electrical energy by the Ministry of Industry and Trade of Vietnam dat. 30/11/2016 (2016)

4. S.P. Anichkov, III-rd International Correspondence Scientific Conference "Current Issues of Modern Engineering and Technology", Collection of reports, 169 p. (2011)

5. S.S. Husen, P.J. Patel., A literature review and industrial survey on active power filter. IJEDR 2, no 1, 118-125 (2014)

6. B. Singh, R. Al-Haddad, A. Chandra., A review of active filters for power quality improvement, IEEE Trans. 46, no. 5, 960-971 (1999)

7. M.El-Habrouk., M.K Darwish, P .Mehta., Active power filter: A review. IEE proc. 147, no. 5, 403-413 (2000)

8. Hideaki Fujita., An approach to harmonic currentfree $A C / D C$ power conversion for large industrial loads: The integration of a series active filter with a double-series diode rectifier, IEEE Trans. 33, no. 5, 1233-1240 (1997) 
9. F.J. Gimeno-Sales, A. Antonio., Achieving maximum efficiency in three-phase systems with a shunt active power compensator based on IEEE Std. 1459, IEEE Trans. 23, no. 2, 812-822 (2008)

10. Z. Wang, Q. Wang, W. Yao and J. Liu., A series active power filter adopting hybrid control approach, IEEE Trans. 16, no. 3., pp. 301-309 (2001)
11. G. Blajszczak., Direct method for voltage distortion compensation in power networks by series converter filter, IEE proc. 142, no. 5, 308-312 (1995)

12. GOST 30804.4.7-2013, Electromagnetic compatibility of technical equipment. General guide on harmonics and interharmonics measuring instruments and measurement for power supply systems and equipment connected to them (2013) 